\title{
INCONSCIÊNCIA DOS CONSTRUTORES FRENTE À GESTÃO AMBENTAL NO CANTEIRO DE OBRAS: ESTUDO DE CASO NA REGÃO SUL DE JOÃO PESSOA/PB
}

\author{
Robson Arruda dos Santos \\ Instituto Federal de Educação, Ciência e Tecnologia da Paraíba - Campus de Patos., robson.santos@ifpb.edu.br
}

http://dx.doi.org/10.5902/223613087204

\section{RESUMO}

A construção civil é um dos setores industriais mais antigos, com significativa participação no Produto Interno Bruto/PIB brasileiro. Porém, encontram-se canteiros de obras onde a tecnologia construtiva empregada é precária, favorecendo o desperdício na execução das suas obras, gerando um grande volume de Resíduos da Construção e Demolição/RCD. O escopo deste trabalho consiste na análise da consciência ambiental dos gestores das empresas da construção em João Pessoa/PB, visto que a gerência dos canteiros de obras não depende apenas dos engenheiros civis. As informações foram obtidas através de entrevistas aos representantes de cinco construtoras e do Sindicato da Indústria da Construção Civil/SINDUSCON-JP. Os resultados das entrevistas mostraram que apenas duas das empresas consultadas eram conhecedoras da legislação acerca de RCD e diziam fazer o gerenciamento destes, sendo que o representante de outra empresa ao menos conhecia as resoluções do Conselho Naconal de Meio Ambiente/CONAMA. Assim, identifica-se uma deficiência dos gestores das empresas da construção consultadas em relação à gestão de RCD.

PALAVRAS-CHAVE: Construção civil, construtor, gerência de obras.

\section{ABSTRACT}

\section{UNCONSCIOUSNESS OF BUILDERS FRONT THE ENVIRONMENTAL MANAGEMENT OF CONSTRUCTIONS SITES: A CASE STUDY IN THE SOUTHERN REGION OF JOÃO PESSOA / PB}

The construction industry is one of the oldest industries, with significant participation in the Brazilian Rough Product Internal. However, there are construction sites where construction technology employed is precarious, favoring waste in the execution of their works, generating a large volume of RCD. The scope of this paper is to analyze the environmental awareness of managers of construction companies in João Pessoa / PB, since the management of construction sites depends not only civil engineers. Information was obtained through interviews with representatives of five builders and SINDUSCON-JP. The results of the interviews showed that only two of the companies surveyed were knowledgeable about the legislation of RCD and said make the management of these, and the representative of another company no knew the CONAMA resolutions. Thus, it identifies a deficiency of managers of construction companies consulted in relation to the management of RCD.

KEY-WORDS: Civil construction, builder, management the construction site. 


\section{INTRODUÇÃO}

A indústria da construção civil ocupa posição de destaque na economia nacional, sendo responsável por uma parcela significativa do Produto Interno Bruto (PIB) do país. Dados recentes indicam que o macrocomplexo construção civil responde por $15 \%$ do PIB nacional (CONSTRUBUSINESS, 2003 apud SOUZA, 2004).

O crescimento do mercado da construção civil, em todo o país, fez surgir muitas empresas no subsetor de edifcações. Assim, empresários de outros setores industriais passaram a investir na construção. As gerências dessas empresas são, na maioria dos casos, realizadas por pessoas que não são da área técnica, sendo assim não se apropriam de certos casos peculiares do setor em que estão atuando, desconhecendo leis importantes para a satisfatória atuação da empresa no mercado, que atenderiam às demandas ambientas e sociais. Logo, faz-se necessário estudar o desempenho desses gestores quanto à sua preocupação com o meio ambiente, para ter-se um panorama da situação do impacto causado na região pelas empresas das quais são responsáveis.

Tomando como referência a tecnologia empregada pela construção civil no Brasil, esta, aplicada normalmente, acaba favorecendo o desperdício na execução das suas obras. Fazendo uma comparação entre a quantidade de resíduos proveniente de novas edificações, em países desenvolvidos e no Brasil, temos que o Brasil gera em torno do triplo do montante de resíduos gerados nos países desenvolvidos, $300 \mathrm{~kg} / \mathrm{m} 2$ edificado (MONTEIRO, 2001). Pesquisas estimam que o lixo resultante da construção, manutenção e demolição de casas e edifícios, representam cerca de $40 \%$ a $60 \%$ do resíduo sólido urbano das grandes cidades (PINTO, 2005).

A resolução 307 do Conselho Nacional do Meio Ambiente/CONAMA, de 5 de Julho de 2002, estabelece a obrigatoriedade da execução de um projeto que gerencie os resíduos sólidos provenientes de todos os projetos de obras submetidos à aprovação nos dos órgãos competentes por parte do seu responsável, esta resolução entrou em vigor em 2 de janeiro de 2003, como está estabelecido no seu Art. 14. A mesma faz algumas classificações acerca dos resíduos oriundos da construção civil, dividindo-os em quatro classes: classe A (resíduos reutilizáveis ou recicláveis); classe B (resíduos recicláveis para outras destinações); classe C (resíduos para os quais não foram desenvolvidas tecnologias ou aplicações economicamente viáveis que permitam a sua reciclagem/recuperação); e classe $D$ (resíduos perigosos oriundos do processo de construção) (BRASIL, 2002).

O crescimento populacional e o acelerado processo de urbanização das cidades têm contribuído para a geração de grandes volumes de Resíduos de Construção e Demolição/RCD, colocando a indústria da construção civil no centro das discussões de um desenvolvimento sustentável em suas diferentes dimensões (SOUZA, 2004). Em decorrência da necessidade dessa discussão sobre sustentabilidade, este trabalho aborda a consciência ambiental dos construtores em João Pessoa/PB visto a necessidade de combater a geração descontrolada, bem como enfatizar a gestão desses resíduos, promovendo assim, a sustentabilidade no canteiro de obras.

O escopo deste trabalho consiste na análise da consciência (ou falta desta) ambiental dos gestores das empresas da construção em João Pessoa/PB. As informações foram obtidas através de entrevistas aos representantes de cinco construtoras e do SINDUSCON-JP. Os resultados das 
entrevistas mostraram um cenário que gera uma preocupação com a atuação dos "comandantes" da industria da construção civil, de grande importância e grande impactante ao meio ambiente.

\section{METODOLOGIA}

A pesquisa foi realizada com o Sindicato da Construção Civil de João PessoaPB/SINDUSCON-JP e cinco empresas construtoras da cidade, com obras na região sul da cidade. As informações foram obtidas através de entrevista com um representante da empresa e um superintendente do SINDUSCON-PB. Priorizou-se a entrevista com um representante da empresa que ocupasse algum cargo gerencial, para se analisar a consciência ambiental do construtor frente ao gerenciamento dos Resíduos da Construção e Demolição/RCD, objetivo deste trabalho.

A pesquisa foi realizada por meio de entrevista aos dirigentes das organizações, sindical e comercial, estudas neste trabalho. Tratou-se de uma pesquisa qualitativa, com amostra de 5 empresas de construção civil, que segundo a Câmara Brasileira da Indústria da Construção/CBIC (2003) enquadra-se em empresa de médio porte, de 100 a 499 funcionários.

A entrevista consistiu em perguntas objetivas direcionadas ao Sindicato da Indústria da Construção Civil de João Pessoa/SINDUSCON-JP e às empresas construtoras. As perguntas abrangiam a temática geral sobre a responsabilidade socioambiental, contudo mais especificamente o gerenciamento dos resíduos gerados nos canteiros de obras, visto que as empresas consultadas atuam no subsetor de edificações.

O questionário aplicado foi dividido em dois focos de análise: se os responsáveis pelas construtoras têm conhecimento da legislação a nível nacional (CONAMA, ABNT) e a lei municipal 11.176/2007; se têm um plano de gerenciamento de resíduos gerados em suas obras.

\section{LEGISLAÇÃO VIGENTE SOBRE GESTÃO DE RESÍDUOS DA CONSTRUÇÃO CIVIL}

O princípio da prevenção é basilar em Direito Ambiental, concernindo à prioridade que deve ser dada a medidas que evitem o nascimento de atentados ao ambiente, de maneira que sejam reduzidas ou até eliminadas as causas de ações suscetíveis de alterar a sua qualidade (MILARÉ, 1998).

Em seu Capítulo VI, relativo ao meio ambiente, Art. 225, a Constituição preconiza que:

"Todos têm direito ao meio ambiente ecologicamente equilibrado, bem de uso comum do povo e essencial à sadia qualidade de vida, impondo-se ao poder público e à coletividade o dever de defendê-lo e preservá-lo para as presentes e futuras gerações".

A construção civil dispõe de várias leis e resoluções direcionadas à questão dos resíduos por ela gerados: resolução CONAMA no 307, de 5 de julho de 2002 e no 348, de 16 de agosto de 
2004 e as normas da Associação Brasileira de Normas Técnicas/ABNT, NBR 15112, NBR 15113, NBR 15114, NBR 15115 e NBR 15116.

A resolução CONAMA no 307, estabelece diretrizes, critérios e procedimentos para a gestão dos resíduos da construção civil, disciplinando as ações necessárias de forma a minimizar os impactos ambientais. A resolução CONAMA no 348 altera a 307, incluindo o amianto na classe de resíduos perigosos.

As normas da ABNT apresentam diretrizes que contemplam em suas determinadas áreas de estudo as normas:

Quadro 1 - Normas da ABNT relacionadas à RCD

\begin{tabular}{|c|c|}
\hline NORMA & TítULO \\
\hline NBR 15112 & $\begin{array}{c}\text { Resíduos da construção civil e resíduos volumosos - áreas de } \\
\text { transbordo e triagem -Diretrizes para projeto, implantação e } \\
\text { operação }\end{array}$ \\
\hline NBR 15113 & $\begin{array}{r}\text { Resíduos sólidos da construção civil e resíduos inertes - Aterros - } \\
\text { Diretrizes para projeto, implantação e operação }\end{array}$ \\
\hline NBR 15114 & $\begin{array}{c}\text { Resíduos sólidos da construção civil - Áreas de recliclagem - } \\
\text { Diretrizes para projeto, implantação e operação }\end{array}$ \\
\hline NBR 15115 & $\begin{array}{c}\text { Agregados reciclados de resíduos sólidos da construção civil - } \\
\text { Execução de camadas de pavimentação - Procedimentos }\end{array}$ \\
\hline NBR 15116 & $\begin{array}{c}\text { Agregados reciclados de resíduos sólidos da construção civil - } \\
\text { Utilização em pavimentação e preparo de concreto sem função } \\
\text { estrutural - Requisitos }\end{array}$ \\
\hline
\end{tabular}

\section{TECNOLOGIA PARA TRATAMENTO DE RESÍDUOS}

O que se tem hoje acerca do uso de tecnologia no gerenciamento de resíduos é muito vasto. Quando se trata de resíduos gerados pela construção civil, outras engenharias podem dá sua contribuição para o reaproveitamento destes. 


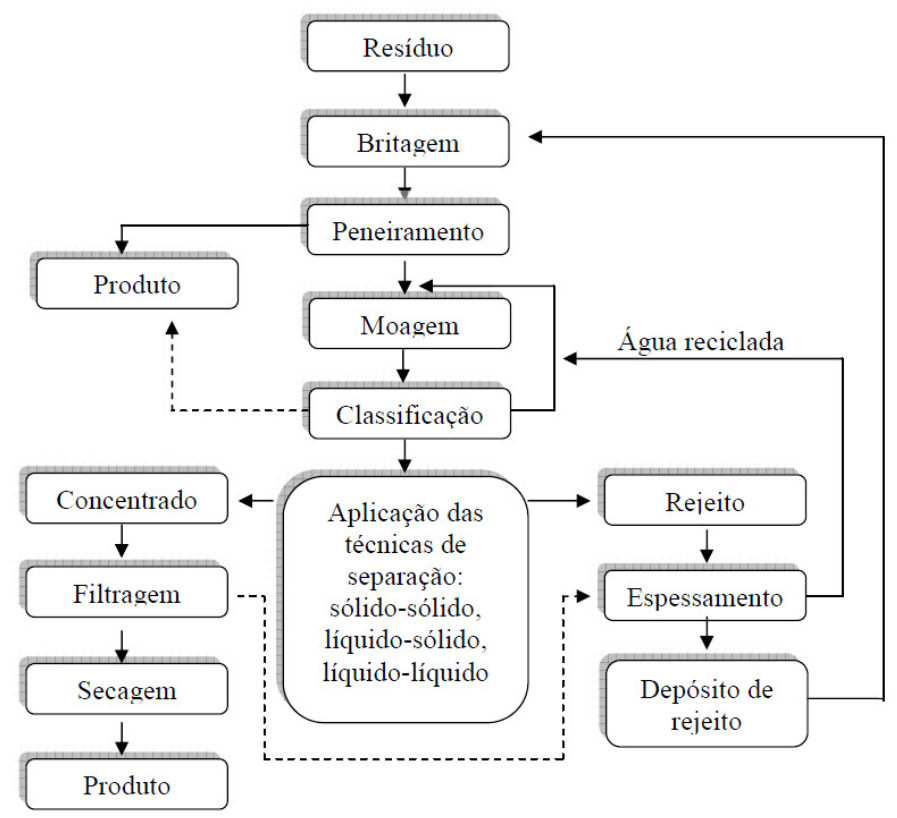

Figura 1 - Esquema de tratamento de rejeito

Um caso particular de aplicação de tecnologia entre engenharias é o uso de técnicas de processamento mineral para separar e classificar resíduos. O processamento mineral ou tratamento de minérios dispõe de uma gama de técnicas usadas para concentrar minerais fisicamente que podem ser aplicadas em sua totalidade para o gerenciamento de resíduos da construção civil.

Podemos citar algumas técnicas que podem ser utilizadas com sucesso para o tratamento de resíduos, são elas: cominuição, peneiramento, concentração gravimétrica, magnética, eletrostática, espessamento, filtração, flotação e a floculação seletiva.

O esquema acima (Figura 1) resume o tratamento de rejeito por meio das técnicas de processamento mineral.

\section{GESTÃO DA PRODUÇÃO NA CONSTRUÇÃO CIVIL}

A Norma Brasileira NBR-1367 define canteiro de obras como sendo um conjunto de "áreas destinadas à execução e apoio dos trabalhos da indústria da construção, dividindo-se em áreas operacionais e áreas de vivência" (ABNT, 1991).

O processo de produção na construção é marcado, em muitas empresas construtoras, por falta de planejamento, seja em nível estratégico, tático ou operacional. Essa situação compromete a qualidade do empreendimento, uma vez que na execução deste serão encontrados muitos imprevistos e ações pontuais de reparação de erros. 
Para cumprir o que estabelece a legislação acerca da gestão dos RCD é preciso investir em um sistema de gestão da obra como um todo. No Art. 4ํ da Resolução CONAMA 307 explicita que se deve haver um trabalho de prevenção para minimizar a geração dos resíduos, o objetivo prioritário é a não geração de resíduos e, secundariamente, a redução, a reutilização, a reciclagem e a destinação final.

O trabalho da gestão dos RCD começa muito antes da execução da obra, deve ter origem nas primeiras etapas de planejamento, pois a definição da tecnologia construtiva a ser utilizada é crucial para que não haja desperdício no canteiro de obras.

Serra (2006) propõe que uma abordagem logística que deve ser considerada durante todo o desenvolvimento do ciclo de produção do empreendimento, ou seja, desde a concepção do mesmo até a fase de execução. Para colocar em prática essa abordagem logística, segundo a autora, deve haver uma integração entre todos os agentes que participam da ação, ou seja, construtor, engenheiro, arquiteto, trabalhador.

O quadro abaixo mostra alguns tópicos do plano logístico da produção proposto por Serra (2006) que se pode aplicar para garantir a aplicação da legislação sobre RCD.

\section{Quadro 2 - Logística de produção para construção civil, SERRA (2006)}

\begin{tabular}{|c|c|}
\hline Ciclo de produção & Diretrizes e Ferramentas gerenciais \\
\hline Projeto & $\begin{array}{l}\text { Diretrizes de logística para a concepção Análise de alternativas de tecnologia Definição do } \\
\text { plano de ataque da obra } \\
\text { Projeto para produção } \\
\text { Projeto do canteiro de obras } \\
\text { Projeto as built }\end{array}$ \\
\hline Planejamento & $\begin{array}{c}\text { Cronograma de consumo de materiais } \\
\text { Cronograma de equipamentos } \\
\text { Histograma da mão-de-obra própria } \\
\text { Cronograma de subempreiteiros } \\
\text { Cronograma de implantação de medidas de segurança }\end{array}$ \\
\hline Suprimentos & $\begin{array}{c}\text { Especificações de materiais } \\
\text { Planos de entrega dos materiais no canteiro de obras } \\
\text { Normas para aquisição de suprimentos } \\
\text { Qualificação de fornecedores de materiais e serviços } \\
\text { Apropriação de índices de perdas e desperdícios de materiais }\end{array}$ \\
\hline Execução & $\begin{array}{c}\text { Plano de execução de serviços nos pavimentos } \\
\text { Documentação, implantação e manutenção do sistema de informações } \\
\text { Normas de segurança e saúde do trabalho }\end{array}$ \\
\hline
\end{tabular}

Fonte: Adaptado de Serra (1997) 
O quadro 2 mostra as ferramentas gerenciais para cada ciclo de produção na construção civil, que se seguido configura um grande avanço para diminuição da geração de resíduos nos canteiros de obra. Principalmente nos ciclos de projeto e planejamento deve se atentar para um plano de gerenciamento dos resíduos, onde se definiria as ações de coleta seletiva na obra, reaproveitamento do resíduo, educação ambiental dos trabalhadores, disposição final correta, etc.

Assim, vemos que para conseguir minimizar a geração de RCD no canteiro de obras é preciso que, principalmente, o construtor deve estar atento ao cumprimento da lei e investir em um processo produtivo dinâmico e eficaz, para evitar o desperdício e evitar o alto volume de geração de resíduos provenientes da construção.

\section{RESULTADOS: SINDUSCON-JP E EMPRESAS CONSTRUTORAS}

Com relação ao SINDUSCON-JP, foi perguntado se há alguma política dentro do sindicato que proporcione às empresas sindicalizadas alguma capacitação concernente ao cumprimento da Lei Municipal № 11.176, de 10 de Outubro de 2007, da cidade de João Pessoa/PB. Uma superintendente do sindicato respondeu que no momento o único foco dado relativo à gestão dos RCD é uma comissão que tem trabalhado expondo a problemática e apontando soluções para o caso das empresas. A superintendente enfocou que a referida comissão é recente e que até o momento realizou apenas uma ação.

A construtoras consultadas neste trabalho atuavam em obras na região sul da cidade de João Pessoa, com empreendimentos de padrão médio; as construtoras eram novas no mercado, não possuíam estrutura para assumir grandes edificações. Esse fato é de bastante relevância, visto os resultados insatisfatórios quanto à atuação das construtoras na região. Identificou-se pouca preocupação destas com as questões ambientas, consequentemente, com a comunidade no entorno de suas obras. 


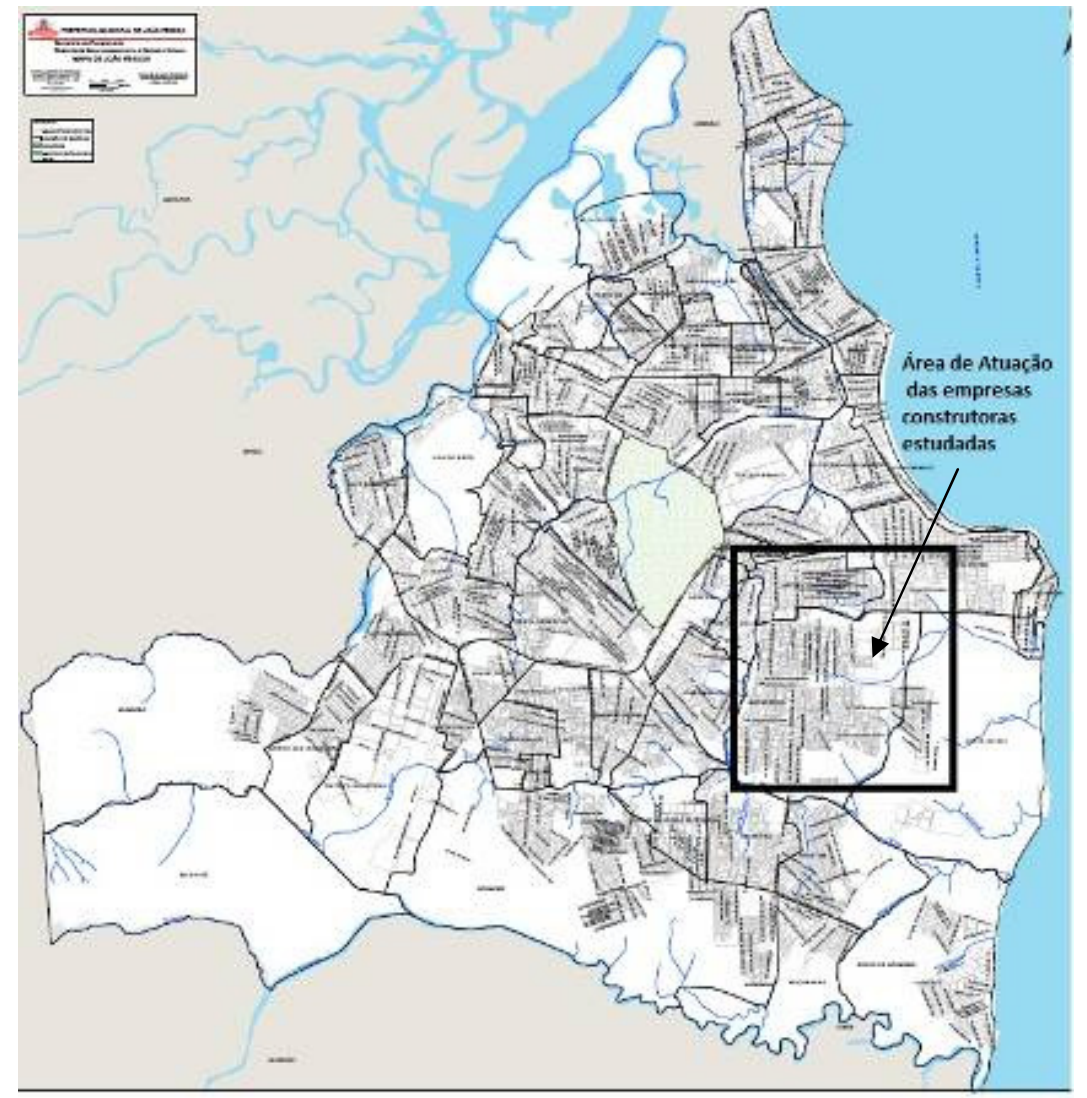

Figura 2 - Delimitação da área de estudo - Região Sul de João Pessoa-PB

As empresas consultadas mostraram-se com pouco conhecimento da legislação vigente quanto ao gerenciamento de RCD, seja a nível nacional ou municipal. Em uma das construtoras a diretora quando indagada sobre o conhecimento da Lei Municipal 11.176, mostrou completamente desconhecedora das questões tratadas nesta, desconhecendo até a Resolução 307 do CONAMA. Em relação aos resíduos gerados pelas obras geridas pela construtora, a diretora falou ser a única prática da empresa, ligar para o Disk Entulho, não fazendo nenhuma separação prévia dos resíduos.

Mesmo desconhecendo a qual legislação deve cumprir, a diretora da empresa supracitada mostrou um plano de gerenciamento de resíduos gerados na construção, este plano foi exigência da Secretaria Municipal de Meio Ambiente de João Pessoa/SEMAM para obtenção da licença de um empreendimento da construtora, sendo que a empresa, por esta imposição, fará um plano de gerenciamento de resíduos para todas as futuras obras, segundo a diretora da empresa.

Apenas duas das empresas mostraram-se bem informadas sobre a política de gestão de resíduos, em que a pessoa entrevistada utilizava-se de termos técnicos da temática em suas colocações corretas, mostrando que a empresa realmente conhece a legislação. Quanto à execução dos planos gerenciais dos RCD, as empresas também mencionaram o Disk Entulho. Verifica-se um diferencial em relação às outras construtoras; essas empresas fazem a separação 
dos resíduos no canteiro de obras, assim facilita o beneficiamento destes pela USIBEN (Usina de Beneficiamento de Resíduos Sólidos de João Pessoa) e quando possível é reciclado em outras obras da empresa.

Quanto aos Programas de Gerenciamento de Resíduos da Construção Civil, todas as empresas apresentam o documento, contudo, apenas $40 \%$ realmente executam o que está disposto neste. Os outros apresentam o PGRCC apenas para fins de fiscalização. É importante ressaltar que as obras eram de pequeno e médio porte, localizadas na região sul da cidade de João Pessoa.

Por fim, ressalta-se que a amostra representa a realidade da região sul da capital paraibana. Por não haver edificações verticais de alto padrão, predomina-se no mercado da região empresas de pequeno e médio porte, em que estas não possuem em sua maioria, políticas de segurança, ambiental e qualidade implantadas, resultando no que foi exposto neste trabalho.

\section{CONSIDERAÇÕES FINAIS}

O mercado da construção civil em João Pessoa/PB é predominantemente formado por empresas construtoras de pequeno porte, com isso a tecnologia empregada favorece o desperdício de material, resultando num grande impacto a sociedade através da geração e principalmente o descaso na disposição final e tratamento dos RCD.

Os resultados encontrados neste trabalho corroboram com o que expõe Degani e Cardoso (2004), quando dizem que

Percebe-se que ainda são poucas as empresas comprometidas com a questão ambiental. A grande maioria aguarda o surgimento e fortalecimento de outras pressões externas e de benefícios que as estimulem a atuar sustentavelmente.

Das cinco empresas consultadas apenas duas eram gerenciadas por profissionais da área da construção civil, sendo estas as que tiveram melhor avaliação na entrevista. A formação dos gerentes dessas empresas certamente contribuiu para sua preocupação com a responsabilidade socioambiental, pois conhecem o problema. A empresa que seu representante não conhecia ao menos o CONAMA mostrou-se interessado em conhecer sobre a legislação, porque no momento da entrevista também era feito um trabalho de conscientização ambiental.

O SINDUSCON está buscando suprir essa necessidade dos empresários da construção civil em adquirir conhecimento técnico acerca da gestão dos resíduos da construção civil, mas essa tarefa pode ser complicada por falta de uma base que estruture esse conhecimento técnico, pois em muitos casos os gestores das empresas de construção civil não têm formação na área.

Por fim, ao mostramos a legislação que trata dos resíduos da construção civil, facilmente identificamos que o problema não está na falta de leis que direcionem as atividades de gestão ou tecnologia disponível, mas na falta de conhecimento desta. É preciso saber o que dizem as normas, leis e resoluções, para que haja o correto dimensionamento da obra, racionalizando, para evitar o excesso de resíduos e a estes dá o devido tratamento e disposição final. 


\section{REFERÊNCIAS BIBLIOGRÁFICAS}

BRASIL, Associação Brasileira de Normas Técnicas/ABNT. NBR 1367 - Áreas de vivência em canteiros de obras. 1991.

BRASIL. Resolução CONAMA no. 307, de 5 de julho de 2002. Estabelece diretrizes, critérios e procedimentos para a gestão dos resíduos da construção civil. Diário Oficial da União, Brasília, DF, 2002.

CIMINELLI, R.R. Recursos Minerais Industriais. In: Geologia, Tectônica e Recursos Minerais do Brasil, Cap. IX. Brasília, 2003.

CONSTRUBUSINESS. Agenda para o setor. Sinduscon-SP. In: SEMINÁRIO DA INDÚSTRIA BRAILEIRA DE CONSTRUÇÃO, 2003, São Paulo. Apresentações. São Paulo: Sinduscon, 2003.

DEGANI, C. M.; CARDOSO, F. F. Aplicabilidade de sistemas de gestão ambiental em empresas construtoras de edifícios. Boletim Técnico da Escola Politécnica da USP, Departamento de Engenharia de Construção Civil. EPUSP, 2004.

MARIANO, L.S. Gerenciamento de resíduos da construção civil com reaproveitamento estrutural: Estudo de caso de uma obra com 4000 m2. Curitiba, 2008. Dissertação de mestrado - UFPR, 2008.

MILARÉ, E. Princípios fundamentais do direito do ambiente. Justitia. São Paulo, 59 (181/184). Jan/dez. 1998. Disponível em: <http://www.justitia.com.br/revistas/w71d84.pdf>. Acesso em: 10 set. 2012.

MONTEIRO, J. H. P. Manual de gerenciamento integrado de resíduos sólidos. Rio de Janeiro: IBAM, 2001.

PINTO, T. P. Gestão ambiental de resíduos da construção civil: a experiência do SindusCon-SP. São Paulo, Obra Limpa: I \& T: SindusCon-SP, 2005.

SERRA, S. M. B.; OLIVEIRA, I. L. Análise da Organização de Canteiros de Obras. Anais do XI Encontro Nacional de Tecnologia do Ambiente Construído, Florianópolis, 2006.

SOUZA, U. E. L.; PALIARI, J. C.; AGOPYAN, V.; ANDRADE, A. C. Diagnóstico e combate à geração de resíduos na produção de obras de construção de edifícios: uma abordagem progressiva. Revista Ambiente Construído, Porto Alegre, v. 4, n. 4, p. 33-46, out./dez. 2004. 